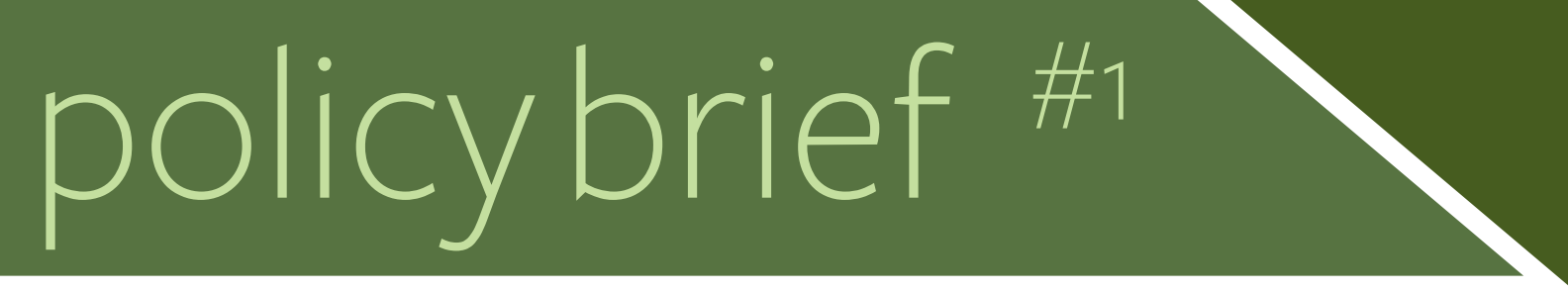

\section{INDIA'S URBAN ECONOMY Generating Employment and Sustaining Growth}

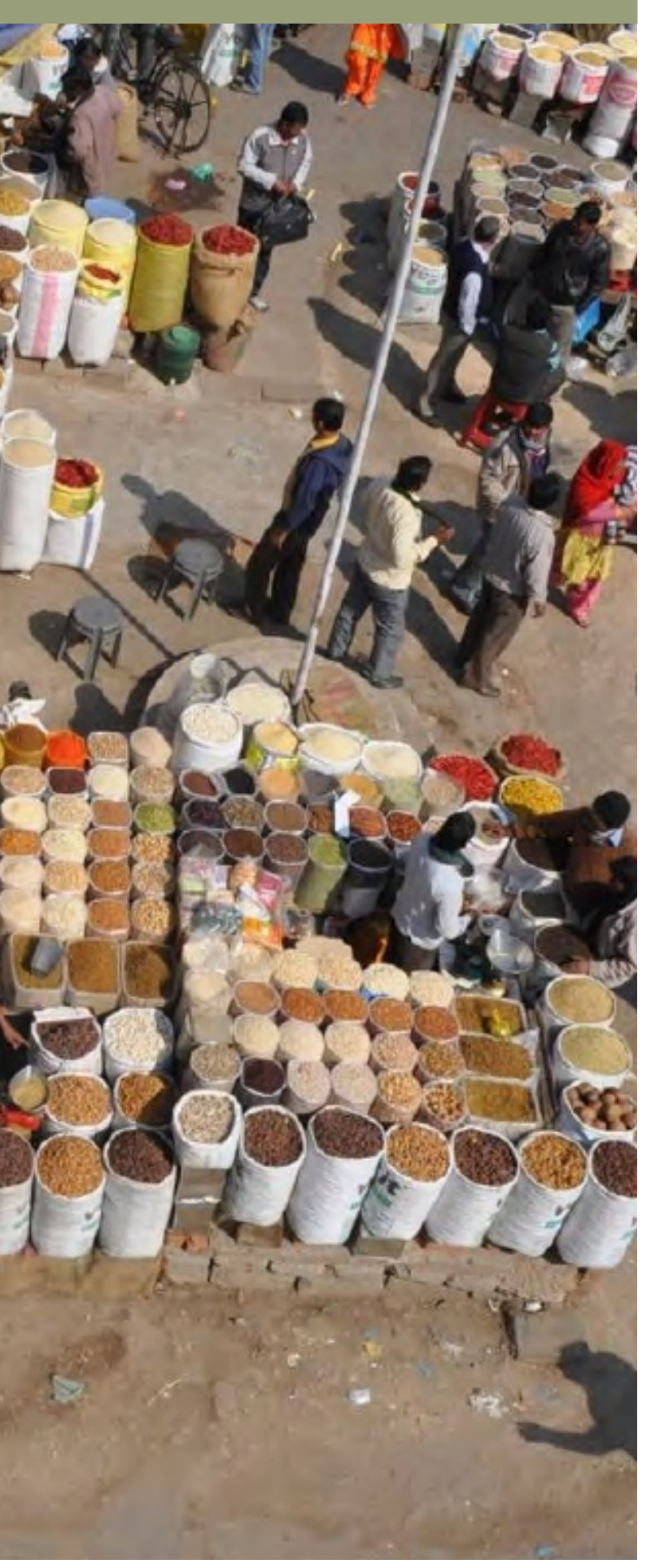

Urban areas in India are currently imagined as growth engines, which will generate a surplus that can be invested in redistribution schemes targeting the rural and urban poor. To achieve growth that can be sustained over the medium and long term, however, an explicit focus on employment is required along with growth. A labourintensive growth pathway is essential to create opportunities for our large, unskilled workforce, and to allow India to simultaneously achieve output growth as well as poverty reduction.

Cities need to be at the forefront of this transition-additional employment generation in the future will come from urban areas. However, the problem is that India's growth over the past decade has been capital- and skill-intensive and has not led to sufficient employment opportunities. This is despite sustained policy efforts to promote industrialisation that could lead to job creation. In fact, most of the new jobs created in urban areas recently have been in the informal services sector and in construction. A focus on urban employment is essential to unlock the potential of India's urban economy and benefit rural areas.

\section{Key Trends}

32\% OF INDIA'S POPULATION LIVES IN URBAN AREAS AS OF 2011

The past decade was the first time since Independence when more people were added to urban than rural areas, primarily due to the reclassification of settlements from rural to urban. This has implications for the emerging nature of urbanisation, as one-third of urban residents now live in small and medium cities with population less than $1,00,000$.

\section{CITIES ACCOUNT FOR 55\% OF TOTAL OUTPUT IN 2012}

India's economy has undergone a structural transformation in output terms, from being a primarily agrarian economy at the time of Independence, to a largely services-based one today. Following economic liberalisation in 1991, India's economic growth was driven by growth in manufacturing, construction, and the services sector. 
These sectors are largely located in urban areas, and cities now account for 55 per cent of the total output in 2012 (Central Statistical Organisation).

STRUCTURE OF EMPLOYMENT HAS NOT CHANGED AS MUCH, LEADING TO A STRUCTURAL MISMATCHIN THE INDIANECONOMY

More than half of the workforce is still employed in agriculture. Overall, the key trends in employment generation since 1991 are as follows:

- India has experienced jobless growth, with overall workforce participation rates (WPRs) declining from 42 per cent in 1993-94 to 38 per cent in 2011-12, a period of rapid growth in the economy.

- This has also been a period of decline in rural WPR, while urban WPR has been steadily increasing.

- Disaggregating further, we find that the decline in rural WPR and the increase in urban WPR has been driven by changes in female WPR, which has declined in rural areas and increased in urban areas.

- There has been a great degree of informalisation of work during the past decade, and quality of employment is a serious concern, particularly for women.

- These national-level numbers mask significant regional and sectoral variations: since 2004, employment in agriculture has declined while the increase in employment has largely come from the construction and services sectors.

\section{Current Policy Framework and Limitations}

Decisions regarding urban economic development are largely undertaken by state governments and industrial development agencies, with urban local bodies playing a limited role.
The national government is involved in setting policy objectives and priorities through centrally sponsored schemes and programmes. The relevant policies of the national government and their limitations are as follows:

JNNURM was launched in 2005 under MoUD and MoHUPA. Its main objective was to achieve urban reform, provide infrastructure targeted to removing productivity bottlenecks in cities, and deliver basic services to the urban poor. One of the key limitations of JNNURM is that the bulk of funding was directed to only 63 selected million-plus cities and cities of strategic importance, ignoring smaller urban centres. In addition, JNNURM did not explicitly address the employment question.

Deen Dayal Upadhyaya Antyodaya Yojana (DAY) was announced in 2014 by MoHUPA and MoRD, and its scope includes all 4,041 statutory towns, unlike JNNURM. Its main goal is to address urban and rural poverty through skills training for the poor, and financial support for self-employment and selfhelp group (SHG) formation. It is also crucial to generate an adequate number of suitable jobs for workers with skills certification. Financial assistance for self-employment and SHG formation might not be sufficient to facilitate entrepreneurial activity by the urban poor.

Industrial corridors, National Investment and Manufacturing Zones (NIMZs), and Special Economic Zones (SEZs). Policies pertaining to these are drafted by the Ministry of Commercy \& Industry (MoCI) in order to facilitate industry-led economic growth, promote exports and investment, and generate employment. However, adopting the East Asian model of export-oriented industrialisation might not work in the current context because of a slowdown in global demand. In addition, employment in the formal sector in large industrial estates represents only a small fraction of total employment-in 2005, 84 per cent of the manufacturing workforce was concentrated in micro and small establishments with less than 50 workers (Hasan and Jandoc 2010). 


\section{Key Actions}

A focus on employment in urban areas is essential to achieve growth that can be sustained. The following policy actions are recommended in this regard:

\section{FOCUS ONEMPLOYMENT-INTENSIVE GROWTH IN EXISTING CITIES, AND NOT ONLY IN INDUSTRIAL REGIONS}

This is particularly important for small and medium towns, where one-third of the urban population currently resides. The potential for impact in these cities is high as these are settlements where future growth will take place. These also act as links to the rural economy. In order to achieve this, state governments will need to focus on the following set of linked actions:

- Addressing infrastructure bottlenecks, particularly urban infrastructure, housing, and transportation, and thinking through the linkages between work, housing and mobility.

- Ensuring connectivity and power, particularly for small and medium towns. The provision of power to all households is important particularly for the functioning of homebased enterprises.

- Strict adherence to environmental standards and enforcement of pollution norms regarding treatment of effluents before discharge into the environment.

\section{FOCUS ON MICRO, SMALL AND MEDIUM ENTERPRISES AND DOMESTICDEMAND AS THE DRIVER OF INDUSTRIAL GROWTH}

The government needs to focus on small and medium enterprises alongside investing in large industrial estates and regions. Currently, 84 per cent of employment in the industrial sector is concentrated in enterprises with less than 50 workers. However, these enterprises suffer from low productivity because of difficulties in accessing finance, lack of access to markets, inadequate infrastructure, multiplicity of labour laws and issues with compliance, and difficulties dealing with excessive regulations and bureacracy (Planning Commission 2012). The national government needs to step in and relax some of these regulations to facilitate.
Productivity gains for small and medium enterprises, given their tremendous employment generation potential, and institute additional supports in addition to subsidised loans based on their needs. The focus on infrastructure, housing, and transport will also facilitate the growth of small enterprises in existing cities.

In addition, besides promoting exports, industrial policy should focus on domestic demand as a key driver for future growth. This can be facilitated through improvements in physical transportation infrastructure, reduction of transaction costs across states, and promoting domestic savings (Rajan 2014).

\section{ADDRESS THE NEEDS OF WOMEN IN THE WORKFORCE}

Changes in female workforce participation rates are a key driver of overall employment in the economy. If recent trends continue, a significant proportion of new entrants to the urban workforce are likely to be women. State governments, therefore, need to focus on the education and training needs of women in particular, and city governments need to ensure safety and recognise the importance of transportation for facilitating women's work. The addition of women to the workforce is important not only for achieving inclusion, but for growth as well. The East Asian growth 'miracle' was largely propelled by an increase in female participation as well as improvements in education, which led to an increase in the quality as well as quantity of the workforce.

\section{References}

- $\quad$ Anand, S., Revi, A., and Koduganti, J. (2014). Cities as Engines of Inclusive Development, IIHS-RF Paper on Indian Urban Economy, Indian Institute for Human Settlements.

- Hasan, R. and K. R. Jandoc (2010). The Distribution of Firm Size in India: What Can Survey Data Tell Us? ADB Economics Working Paper Series, Asian Development Bank.

- Planning Commission (2012). Report of the Working Group on Micro, Small and Medium Enterprises Growth for 12th Five Year Plan (2012-17). 12th Five Year Plan. New Delhi, Government of India.

- Rajan, R. (2014). Make in India, Largely for India. New Delhi, Reserve Bank of India. 


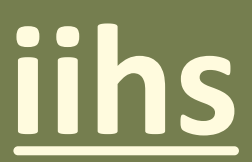

INDIAN INSTITUTE FOR HUMAN SETTLEMENTS
IIHS City Campus

No. 197/36, 2nd Main Road

Sadashiva Nagar

Bangalore 560080 . India

$\mathrm{T}+918067606666$

www.iihs.co.in | info@iihs.co.in 